\title{
A geogrid-reinforced landslide stabilization: 20 years passed
}

\author{
Dimiter Alexiew ${ }^{\text {i) }}$, Anton Plankel ${ }^{\text {ii) }}$ and Graham Thomson ${ }^{\text {iii) }}$ \\ i) Technical Director, HUESKER Synthetic GmbH, 13-15 Fabrikstrasse, Gescher, D-48712, Germany. \\ ii) CEO, 3P Geotechnik ZT GmbH, 117 Arlbergstr., Bregenz, A-6900, Austria. \\ iii) Managing Director, HUESKER Asia Pacific Pte Ltd, 143 Cecil Street, 25-03 GB Building, Singapore.
}

\begin{abstract}
In spring 1994 a landslide occurred on a natural slope of about $25 \mathrm{~m}$ height just below a ski-lift station in the Austrian Alps near Lech. The slid soil mass blocked the road at the toe of slope. The upper part of the sliding surface reached the foundation of the lift station on top of slope destroying the earth platform in front of the station and endangering the entire building.

A quick solution for the slope reconstruction and stabilization had to be developed and executed before the beginning of the next ski season in September. The solution had to meet a wide range of requirements, some of them caused by the specific position in the high mountains. Finally, a geogrid-reinforced full-height slope was designed and constructed reusing the local soils and reconstructing approximately the former natural slope shape before the failure. Note, that at that time the experience with such structures was still modest, some decisions were a bit risky due to the lack of knowledge and were based on engineering judgement.

The system was successfully built in less than two months and is still stable after twenty years of service, say twenty season cycles winter-summer in the Alps.

The problems, boundary conditions, philosophy and design from 1994 are described together with the unknown factors and specific solutions, and the construction technology and experience as well. The current state is shortly described and commented.
\end{abstract}

Keywords: landslide stabilization, mountains, geogrids, long-term experience

\section{INTRODUCTION}

The region of Lech is one of the most famous ski regions in the Austrian Alps (Figure 1). A huge net of ski trails and lifts is available. The latter are an essential technical and economical component and have to be integrated in an optimal way into the natural landscape.

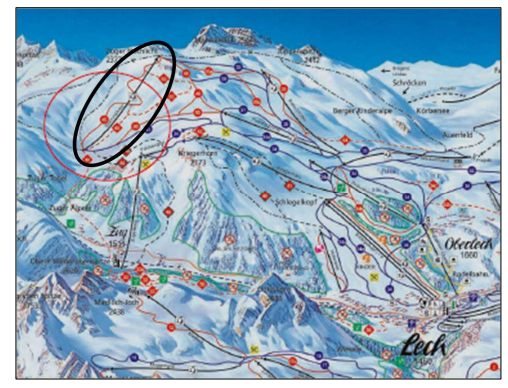

Fig. 1. The ski region of Lech in the Austrian Alps (the Steinmähder Wand is marked).

In spring 1994 a landslide occurred in a natural slope of about $25 \mathrm{~m}$ height just below the lower ski-lift station at the so called Steinmähder Wand (Figure 1).
This lower station is positioned at $1800 \mathrm{mNN}$, the upper one at $2300 \mathrm{mNN}$ (Figure 1).

\section{GENERAL FACTS}

Snow fall usually starts in October and ends in April: this is the ski season. The landslide occurred in summer 1994. There were some days at that time with up to $30 \mathrm{~mm}$ rain per day; such values are believed not

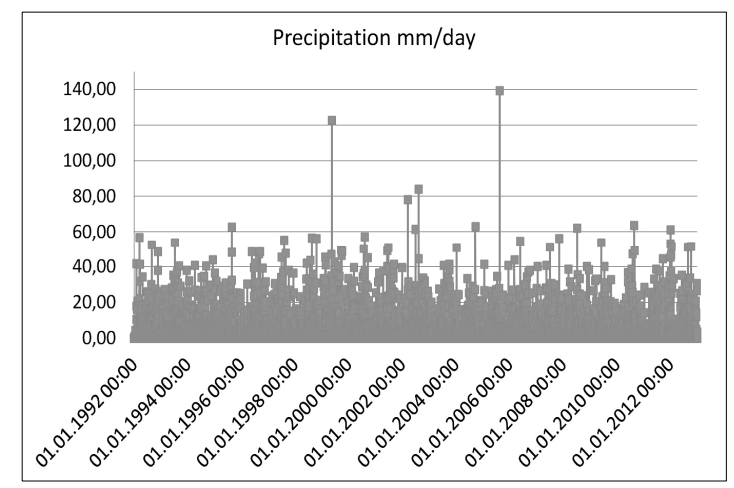

Fig. 2. Overview of precipitation. 
to be critical. The most probable trigger was may be a "global" over-wetting due to massive snow melting on the slopes above (Figure 1). In Figure 2 a precipitation overview is depicted.

The slid soil mass blocked an unpaved but important alpine road at the toe of slope. The upper part of the sliding surface reached the foundation of the lift station on top of slope destroying the earth platform in front of the station and endangering the entire building (Figure 3) despite the micro-piles below the front part of foundation. The width of landslide amounted to ca. 50 $\mathrm{m}$, the height varied from 23 to $25 \mathrm{~m}$.
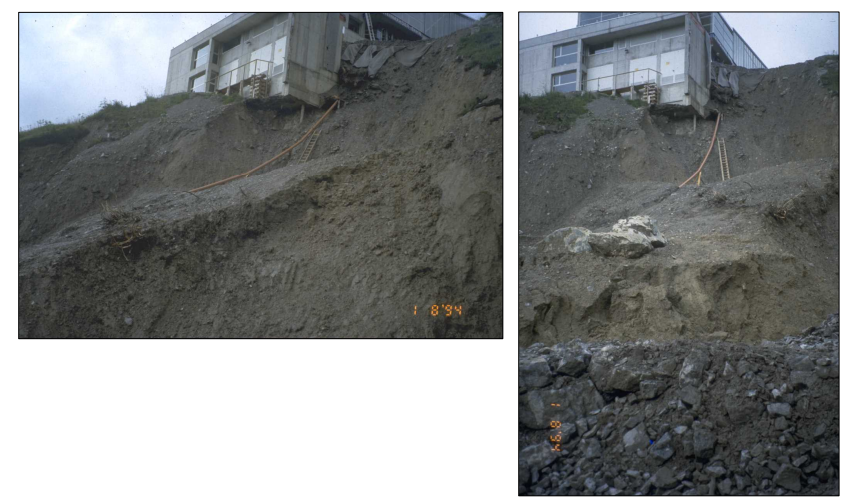

Fig. 3. Part of landslide with endangered lift station.

(Note: in the meantime the problem of landslides and avalanches has increased, Alexiew (2005), Alexiew \& Bruhier (2013)).

\section{GEOTECHNICAL CIRCUMSTANCES}

Approximately in the same position a former smaller lift station had existed for 14 years; the new one was built in 1993, i.e. one year before the landslide occurred. Long-term observations and the geotechnical reports from 1993 did not attest problems in terms of performance or geotechnical aspects. However, because of some intuitive slope stability doubts and the more or less permanent risk of oversaturation, the second author recommended in 1993 a proper drainage and on the safe side the installation of the micro-piles mentioned above.

After landslide neither a soil layer as possibly pre-defined sliding plane (e.g. clay) could be visibly identified, nor concentrated wells (despite some extremely wet areas). The failure surface was three-dimensional, non-planar and quite irregular (Figure 3).

The typical data of the local slope soil were:

talus material, sandy gravelly silt, coefficient of uniformity ca. $\mathrm{C}_{\mathrm{U}}=50$, gravel $22 \%$, sand $27 \%$, fines $51 \%$ (silt 42\%, clay 9\%), unit weight ca. $18 \mathrm{kN} / \mathrm{m}^{3}$, Proctor density ca. $\rho_{\mathrm{d}}=2.07 \mathrm{~g} / \mathrm{cm}^{3}, \mathrm{w}_{\text {opt }}=11.3 \%$. The soil fraction $<2 \mathrm{~mm}$ (fines and sand) possesses an angle of internal friction $\varphi^{\prime}$ peak $=(!) \varphi^{\prime}$ post-peak $=36.5^{\circ}$ (say no indication of "progressive" shear failure tendency) and a cohesion $c^{\prime}=0$ (a bit surprising). The coefficient of permeability had not been tested, but based on granulometry, soil classification and local experience it was obvious, that it is not "free draining".

\section{WHAT AND HOW HAD TO BE DONE}

The slope had to be "repaired" as quickly as possible due to both the endangered lift station and the blocked road. The frame conditions for an "ideal solution" from the point of view of the owner "Skilifte Lech" were:

guarantee in the long term the stability and serviceability of the lift station (a permanent solution),

reconstruct the platform in front of the station,

protect the entire slope against similar problems in future,

reconstruct to the greatest possible extent the natural shape of terrain as prior to failure,

reuse the local soil (slid masses) so far as possible,

minimize the transport (import) of any construction materials in terms of weight and volume,

put the lift station in operation latest end of September (beginning of the ski season), say the time to find an optimal solution, to design it and to built was about two months,

use a simple and adaptive technology avoiding a special contractor's qualification and skills,

"green" solution (vegetated surface),

keep it cheap (!).

The requirements were complex and not easy to meet.

\section{LEVEL OF KNOWLEDGE AND DIFFICULTIES IN 1994}

The solution finding process was very intensive and relatively quick due to the stringent frame conditions mentioned above. A geosynthetic reinforced soil block stabilizing the slope and regenerating the landscape was believed to be generally the best solution. All the thoughts from this time cannot be explained herein due to brevity.

Note, that at that time the experience with geosynthetic reinforced slopes being today a routine was quite modest, and no system like that for landslide stabilization was known to the authors (even to our best knowledge today it had never been built at least in Europe before 1994).

Some additional difficulties were faced:

a. The possible scattering of soil parameters was not known, and there was no time for additional soil testing. There was also no time for analysis of the failure and its reason(s). Thus some hypotheses and assumptions had to be made by engineering judgement and on the safe side.

b. The hydrological situation was not clear enough. Consequently, the motto was "drain as you can drain".

c. There were no standardized or definitely 
recommended sound calculation and design procedures for such systems, not to mention the software (non-)availability.

d. The access to the site was very difficult: only small steep unpaved mountain roads were available.

e. There was no experienced contractor for such a work.

\section{SOLUTION}

A typical simplified cross-section is depicted in Figure 4.

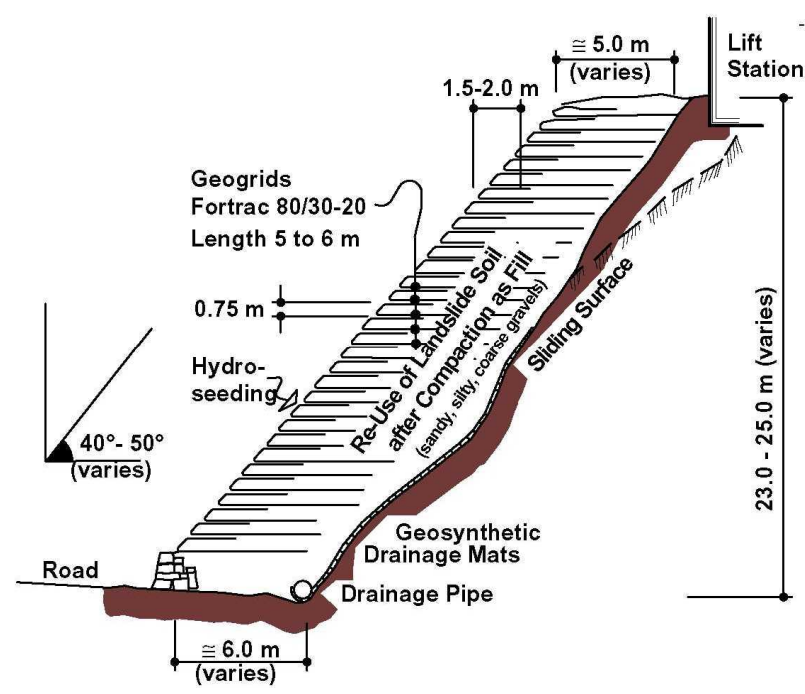

Fig. 4. Typical cross-section of the landslide stabilization solution (geometry generally varied, see e.g. Figure 7).

The solution as depicted is may be the third or fourth (and final) version. Some previous drafts become step by step modified.

Some short comments:

It was decided to reuse totally the local soil (slid mass) as fill (compare Chapters 4 \& 5). The authors were optimistic due to its good compactibility (wide gradation) and its sufficient shear resistance (Chapter 3). At that time such a decision seemed risky: only the use of high-quality non-cohesive completely free-draining fills was the state-of-the-art technology. However, due to the modest permeability intensive drainage had to be foreseen.

Geosynthetic drainage mats were preferred to a gravel layer in the interface to the sliding surface: they are easier to transport and install. The mats were connected to a drainage pipe. They had to be installed upslope vertically in a "zebra" pattern: $1 \mathrm{~m}$ mat, $1 \mathrm{~m}$ spacing, i.e. after each mat there was $1 \mathrm{~m}$ of direct contact of the fill to the local soil. The reason was that usually the interface "mat to soil" has a lower shear resistance (bond) then the internal shear resistance of the contacting soils itself; unfortunately, due to the extremely tight schedule there was no time for testing. Thus, it was believed that the risk of creating an artificial surface prone to sliding in the case of continuous full-area installation is too high.

As geosynthetic reinforcement providing the required stability high-tenacity low-creep polyester geogrids from the Fortrac ${ }^{\circledR}$ family were chosen being easy to transport and install due to their low weight and flexibility.

Due to logistic reasons, the extremely tight time schedule and the not precisely known total final amount of reinforcement it was decided to use a unified single type of geogrid for the entire system, although a differentiation could result in a more cost-efficient solution. The geogrids were $5 \mathrm{~m}$ wide and exhibited based on previous tests a very high coefficient of interaction (bond) to a wide range of soils. There lengths varied typically from $6 \mathrm{~m}$ to $5 \mathrm{~m}$. They had to be installed in the so called "wrap-back" manner using removable formwork without e.g. supporting steel meshes in front, thus creating a "soft" nature-alike reconstituted slope surface to be vegetated by hydro-seeding.

The owner decided that no additional anti-erosion geotextile should be installed at the inner side of the geogrids at the facing (front) as it was suggested by the authors.

For stability analysis and design software under MS DOS was used based on a simplified version of a polygonal block-sliding method in combination with some additional checks using Bishop's method. In 1994 there was no complete specialized software available in the market dealing specifically with geosynthetic reinforcement. Finally, some decisions had to be made by engineering judgment.

For the choice of the unified geogrid (see above) two options seemed possible: a lighter geogrid Fortrac ${ }^{\circledR} 55 / 30-20$ at ca. $0.5 \mathrm{~m}$ vertical spacing and the stronger Fortrac ${ }^{\circledR} 80 / 30-20$ at $0.75 \mathrm{~m}$. The latter option was chosen to make installation, fill compaction and construction quicker. Note that at that time no experience with such a big spacing was available.

Due to brevity no further details can be explained herein.

A fill compaction of at least $\mathrm{D}_{\mathrm{pr}}=98 \%$ was prescribed. The design and technology concept avoided any export or import of soils, steel, concrete etc.: only the light-weight, low-volume geosynthetic rolls had to be transported.

\section{EXECUTION AND EXPERIENCE}

Execution started about mid of August 1994 and was completed just in time end of September. A removable formwork was used for the front. Some construction stages are shown in Figures $5 \& 6$.

Figure 5 shows at a glance all components of the system and the compaction procedure. Note the use of heavy compaction for the $0.75 \mathrm{~m}$ thick fill layers and the installation of drainage mats with a space in between (Chapter 6). One can see (Figure 6) that due to 
the lack of experience (the contractor had never built such a system) and the extreme time pressure the geometry of the first geogrid-soil layers was not really precise. However, because this was not critical for stability and due to the anyway intended nature-alike final shape, this was tolerated.

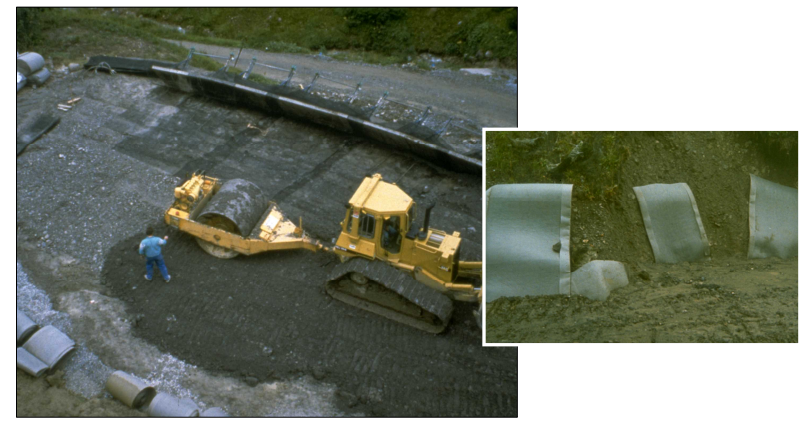

Fig. 5. Construction: first layers, fill compaction by heavy equipment, formwork, geogrids, drainage mats.



Fig. 6. Construction: partial view of the geogrid-reinforced slope. Note the "bellies" of the first layers.

Quality of compaction was controlled at several points at every fill layer.

All the time the structure geometry had to be adapted to reconstruct so far as possible the shape of the previous natural slope (Chapter 4) keeping always the design basics as per Figure 4. This procedure was quite unique: strictly speaking complete precise execution drawings had never existed; instead, engineering judgment and ad hoc decisions were applied. It was a demonstration of the flexibility and adaptation capability of such systems.

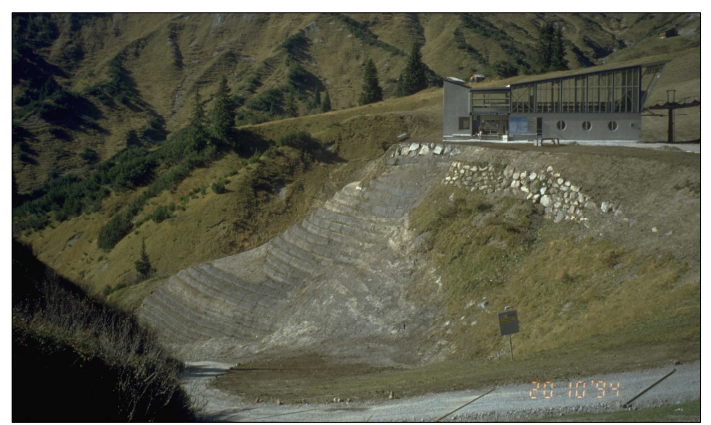

Fig. 7. Geogrid reinforced landslide stabilization just after completion (end of September 1994).

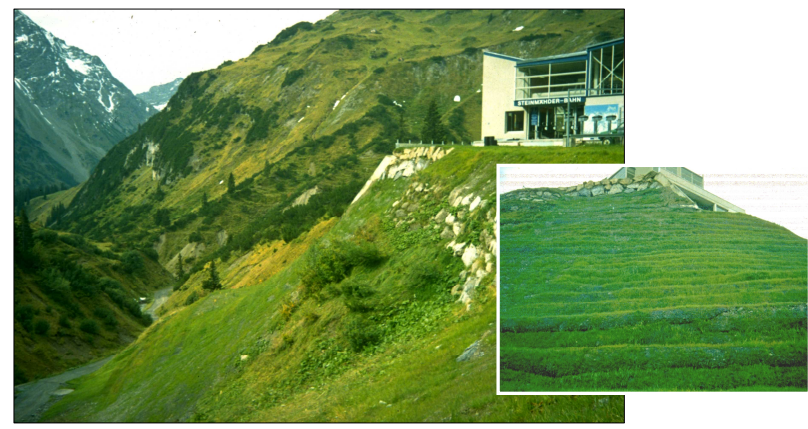

Fig. 8. The system in summer 1995, almost a year after completion and after a winter-spring cycle.

Figures 7 \& 8 show the geogrid-reinforced stabilization just after completion and one year later. It should be noted that considering all the problematic factors and circumstances such a short construction time was a real achievement. It is recognizable how the adapted soft, to some extent irregular 3D-geometry fits successfully the natural alpine landscape.

In summer 1995, after almost a year after construction and after a winter-spring cycle there were no indications of stability or serviceability problems of any type. (Note that a year ago at that time the landslide failure occurred). The hydro-seeding seemed to be quite successful although not perfect.

Then for a very long time the authors had no contact to the project. However, in such cases the motto applies: no news, good news...

\section{AUGUST 2014: TWENTY YEARS LATER}

In August 2014 the first authors had the opportunity to visit the structure again together with the project leader of the owner in 1994 Mr. Manhart being still active.

In Figures 9, $10 \& 11$ the present situation is depicted.

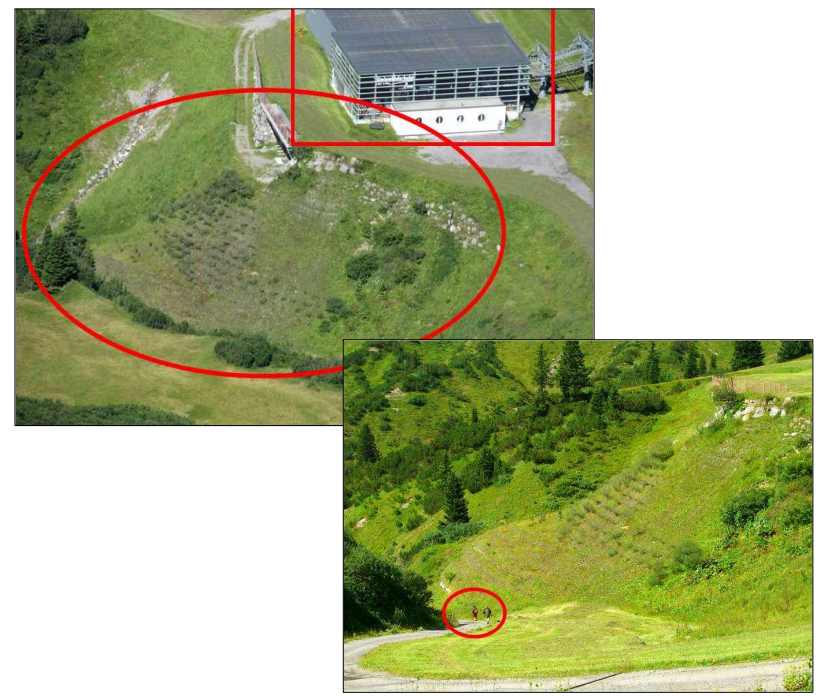

Fig. 9. August 2014: left up: overview, reinforced slope is marked; right down: persons as a scale for the structure. 


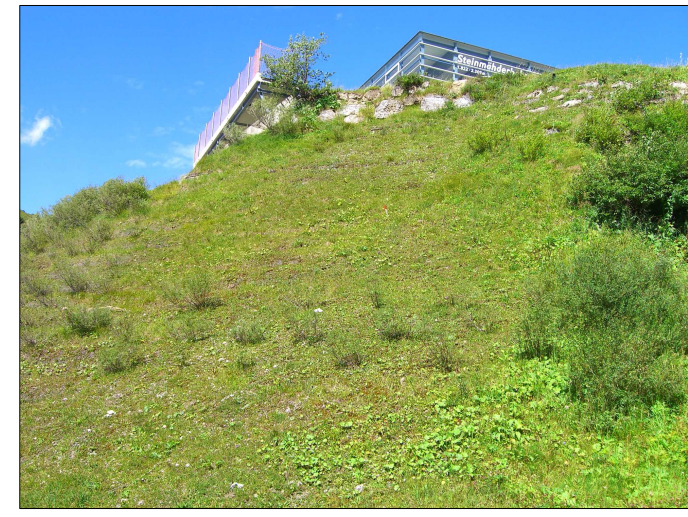

Fig. 10. August 2014: view upslope.

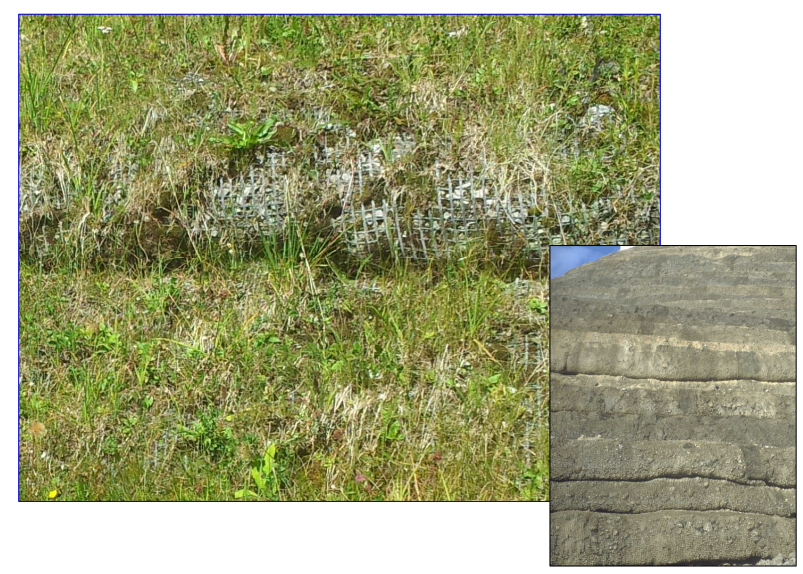

Fig. 11. August 2014: left: zoom of a vertical layer of the geogrid facing with a "belly"; right: same section in September 1994.

By the way: it is interesting to compare Figures 7, 8 $\& 9$ at a glance.

Visually there were no indications of any relevant deformation of any type: neither vertical, nor horizontal. Although no precise measurements had been done over the twenty years passed, the systematic inspections of the owner had attested no problems from the point of view of stability or serviceability of the reinforced slope or of the station foundation on top.

The facing was to more than $90 \%$ vegetated, although only marginal maintenance had been done. In the meantime the typical local vegetation dominated the picture. The only spots with meager vegetation were the almost vertical parts of some "belly" layers (Figure 11). Some erosion of fines was visible (Figure 11) due to the missing anti-erosion geotextile behind the geogrids (decision of the owner in 1994, see Chapter 6). However, this had no further negative consequences. Note, that the completely unprotected geogrids are still intact.

The inspection of the runout of the drainage pipe (Figure 4) showed a small but steady flow of clear water (August!).

In summary: after twenty years in operation the system is completely in a good condition without any additional measures or corrections in that period.

\section{FINAL REMARKS}

It seems that the geogrid-reinforced landslide stabilization structure designed and built in 1994 (say twenty years ago) proves to be generally a successful, efficient and durable solution despite a number of specific disadvantageous circumstances in 1994.

In our opinion this demonstrates the flexibility and robustness of geosynthetic-soil structures.

It is may be the first geogrid application for rehabilitation and stabilization of a landslide.

It is worth to notice that in comparison to today even the design procedures and tools were in 1994 very modest and had to be substituted often by engineering judgment.

In our understanding the positive experience gained should encourage the intensive application of such solutions nowadays especially in consideration of the globally increasing landslide problems due to climate change.

\section{ACKNOWLEDGEMENTS}

The authors appreciate very much the competence, open mind and consistent support of Mr. Manhart from "Skilifte Lech".

\section{REFERENCES}

1) Alexiew D. (2005): Design and construction of geosynthetic-reinforced "slopes" and "walls": commentary and selected project examples. Proc. $12^{\text {th }}$ Darmstadt Geotechnical Conference. Darmstadt Geotechnics No. 13, TU Darmstadt, Institute and Laboratory of Geotechnics, Darmstadt, 167-186.

2) Alexiew D., Bruhier, J. (2013): Some case studies of geosynthetic solutions while dealing with landslides and unstable slopes. Proc. ICLR2013 (Int. Conf. on Landslide Rehab.), Draham, Tunisia. 